the methods of converting alternating current into high voltage direct current are still in the experimental stage, at least when dealing with power in bulk. Lord Kelvin was a great advocate for the transmission of electric power by direct current, and although most of the difficulties in working with alternating current have been overcome since his time, it is interesting to notice that several engineers still think that direct current will be used for trans. mission in the future.

\section{Data of Social and Economic Problems}

IN a recent number of Planning (16 Queen Anne's Gate, London, S.W.1) attention is directed to the lack of necessary data on many urgent social and economic problems. A civilisation has grown up under industrialism which calls for enormous resources of knowledge in order to operate it without constant and painful breakdowns. Yet we neither possess the required knowledge nor are we making at present any adequate effort to get it, although its provision offers no insuperable difficulties. Our whole attitude towards the question is still coloured by the prejudices and assumptions of a pre-scientific and pre-technical age. It has yet to be recognised that the same technique which has produced electricity, wireless, fertilisers and new breeds of plants and animals can, if suitably adapted, produce those social, political and economic inventions which we so desperately need.

WHILE the industrial executive in Great Britain and elsewhere has come to recognise that provision must continually be made for new patterns and new techniques, there is no corresponding awareness or equipment for checking and improving the performance of, say, the machinery of government, the health services or the handling of traffic. Immense problems such as the modern scourge of noise, of smoke and chemical pollution in air and water, of street accidents, of crime, of destruction of amenities and many others are allowed to grow up unchecked and almost unobserved. The problem is how to make effective the many demands for new knowledge which are at present frustrated because they do not promise profit to particular individuals or undertakings although they may involve great savings to the community. Obviously one solution would be a great expansion of State-aided research, but much more thought and inquiry would be needed before concluding that this is the only, or the best, solution.

\section{A New Arctic Island}

THE discovery of a new island in the arctic is now a rare event, but in the Geagraphical Review of January, Mr. V. Stefansson describes what is probably such an occurrence. In September 1931 a party of Eskimo, searching for whales north of Alaska, came to an island on which they went ashore in a position of approximately lat. $71^{\circ} 20^{\prime} \mathrm{N}$., long. $145^{\circ}$ $30^{\prime} \mathrm{W}$. This is about 85 miles north of Flaxman Island and due east of Point Barrow. The island was reported to be about half a mile long and of the same width and to rise to an altitude of about fifty feet. There was some vegetation but no drift- wood. Mr. Stefansson vouches for the reliability of the Eskimo Takpuk who led the party and whose name has been given to the island. Further, he discounts the suggestion that the island was merely earth on floating ice. That part of the Beaufort Sea has been little explored though the nearest soundings, some twenty-five miles to the west, show deep water. The question arises as to the possibility of Takpuk Island being Keenan Land, reported in the 'seventies of last century and placed in various longitudes in about lat. $73^{\circ} \mathrm{N}$., but this seems more than doubtful. Photographs of Takpuk Island are reproduced with the article.

\section{The Australian Geographer}

THE format has been remodelled and the scope changed of the Australian Geographer, the periodical published by the Geographical Society of New South Wales. It is hoped now to publish it more often than once a year and to give special consideration to the work of Australian writers on the geo. graphy of the continent. A special feature will be the continuance in every issue of a bibliography of Australian geographical literature. This feature, which begins with the year 1926 in the current issue (No. 1, vol. 2), should prove of considerable value. Another valuable article is that by Dr. M. Holmes in the Australian geographical environment, which treats the subject in much detail.

\section{Philosophy and Everyday Life}

THE organ of the Philosophical Society of England, the Philosopher, enters on its twelfth year of publication under new editorship and in a new and attractive format. As is pointed out in the opening article, the special branches of science have found exponents capable of interpreting their many recent advances to the general reader, and it is the purpose of the Philosopher in a similar way to interpret current thought in philosophy and to indicate its contacts with the world of to-day. Thus in the issue before us there is an article on "Reason in Action" by Prof. John Macmurray, another on "Reflection and Common Sense" by Prof. A. E. Heath and another by Paul Painlevé, the distinguished French mathematician, philosopher and statesman who died towards the end of last year, on "Civilisation and Modern Science". Students of philosophy will perhaps turn more readily to the "Courses of Study", where notes are given on various aspects of the subject, with suggestions for further reading. There are also reviews and notices of recent books, a section on educational intelligence, a record of meetings of the Philosophical Society and so on. The journal has thus a double appeal, to the layman and to the student, and at the modest price of $6 d$. should have a wide circle of readers. Copies of the Philosopher can be obtained from the Honorary Secretary of the Philosophical Society, 13 Woodlands Road, London, S.W.13.

\section{Physica}

THE first number of the new Dutch periodical Physica (December 1933, pp. 96, published by Martinus Nijhoff, The Hague, 25 guilders yearly) 